\title{
Oxidative Modification of Blood Serum Proteins in Multiple Sclerosis after Interferon Beta and Melatonin Treatment
}

\author{
Monika Adamczyk-Sowa, ${ }^{1}$ Sabina Galiniak, ${ }^{2}$ Ewa Żyracka, ${ }^{3}$ Michalina Grzesik, ${ }^{3}$ \\ Katarzyna Naparło, ${ }^{3}$ Pawel Sowa, ${ }^{4}$ Grzegorz Bartosz, ${ }^{5}$ and Izabela Sadowska-Bartosz ${ }^{3}$ \\ ${ }^{1}$ Department of Neurology in Zabrze, Medical University of Silesia, 3-go Maja St. 13-15, 41-800 Zabrze, Poland \\ ${ }^{2}$ Department of Histology and Embryology, Chair of the Morphological Sciences, University of Rzeszów, Leszka Czarnego 4, \\ 35-615 Rzeszów, Poland \\ ${ }^{3}$ Department of Analytical Biochemistry, Faculty of Biology and Agriculture, University of Rzeszów, ul. Zelwerowicza 4, \\ 35-601 Rzeszów, Poland \\ ${ }^{4}$ Department of Laryngology in Zabrze, Medical University of Silesia, ul. Curie-Skłodowskiej 10, 41-800 Zabrze, Poland \\ ${ }^{5}$ Department of Molecular Biophysics, Faculty of Biology and Environmental Protection, University of Łódź, Pomorska 141/143, \\ 90-236 Łódź, Poland
}

Correspondence should be addressed to Izabela Sadowska-Bartosz; isadowska@poczta.fm

Received 22 May 2017; Accepted 24 September 2017; Published 18 October 2017

Academic Editor: Valentina Pallottini

Copyright (C) 2017 Monika Adamczyk-Sowa et al. This is an open access article distributed under the Creative Commons Attribution License, which permits unrestricted use, distribution, and reproduction in any medium, provided the original work is properly cited.

\begin{abstract}
Multiple sclerosis (MS) is a disease involving oxidative stress (OS). This study was aimed at examination of the effect of melatonin supplementation on OS parameters, especially oxidative protein modifications of blood serum proteins, in MS patients. The study included 11 control subjects, 14 de novo diagnosed MS patients with the relapsing-remitting form of MS (RRMS), 36 patients with RRMS receiving interferon beta- $1 \mathrm{~b}(250 \mu \mathrm{g}$ every other day), and 25 RRMS patients receiving interferon beta- $1 \mathrm{~b}$ plus melatonin (5 mg daily). The levels of $\mathrm{N}^{\prime}$-formylkynurenine, kynurenine, dityrosine, carbonyl groups, advanced glycation products (AGEs), advanced oxidation protein products (AOPP), and malondialdehyde were elevated in nontreated RRSM patients. N'-Formylkynurenine, kynurenine, AGEs, and carbonyl contents were decreased only in the group treated with interferon beta plus melatonin, while dityrosine and AOPP contents were decreased both in the group of patients treated with interferon beta and in the group treated with interferon beta- $1 \mathrm{~b}$ plus melatonin. These results demonstrate that melatonin ameliorates OS in MS patients supporting the view that combined administration of interferon beta- $1 \mathrm{~b}$ and melatonin can be more effective in reducing OS in MS patients than interferon beta-1b alone.
\end{abstract}

\section{Introduction}

Multiple sclerosis (MS) is one of the most widespread chronic inflammatory, demyelinating diseases of the central nervous system (CNS), which leads to damage of myelin and axons. Although the exact cause of MS is unknown, it is considered that genetic predisposition, environmental factors, and abnormal immune response, consisting of delivery of cytokines from lymphocytes including Th1 and Th17 cells, contribute to the pathogenesis of this disease $[1,2]$. In recent years, the factors involved in the etiology of the disease have also included oxidative stress (OS), which is defined as an imbalance between the generation of reactive oxygen species (ROS) and the mechanisms that are responsible for their elimination. It is suggested that the increased generation of ROS and reactive forms of nitrogen (RNS) leads to oxidative and nitrosative stress causing damage to mitochondria and myelin, oligodendrocyte apoptosis, and astrocyte dysfunction [3]. Elevated OS markers were observed in the blood, plasma, and cerebrospinal fluid of patients with relapsingremitting (RRMS) form of MS [4-7] and in the plasma of patients with secondary progressive (SPMS) form of MS 
TABLe 1: Demographic data of the subjects studied.

\begin{tabular}{lcccc}
\hline Group & Control & RRMS INF-beta + MEL & RRMS INF-beta & RRMS untreated \\
\hline Subject number $(n)$ (total $n=86)$ & 11 & 25 & 36 & 14 \\
Age (years) mean \pm SD & $34.54 \pm 9.6$ & $38.16 \pm 8.29$ & $39.49 \pm 10.16$ & $40.65 \pm 10.01$ \\
Female/male number $(n)$ & $6 / 5$ & $18 / 7$ & $26 / 10$ & $7 / 7$ \\
EDSS mean \pm SD & NA & $1.85 \pm 0.75$ & $2.52 \pm 1.14$ & $2.68 \pm 1.11$ \\
Disease duration (years) mean \pm SD & NA & $4.89 \pm 1.41$ & $6.07 \pm 3.97$ & $0.88 \pm 0.65$ \\
Treatment duration (months) mean \pm SD & NA & $29.51 \pm 5.03$ & $28.18 \pm 7.13$ & NA \\
Number of T2 brain MRI lesions (mean \pm SD) & NA & $8.70 \pm 7.54$ & $9.18 \pm 6.56$ & $11.11 \pm 10.94$ \\
Number of T1 Gd $(+)$ brain MRI lesions (mean \pm SD) & NA & $0.52 \pm 0.17$ & $0.66 \pm 0.65$ & $0.86 \pm 0.85$ \\
\hline
\end{tabular}

NA: nonapplicable. Data are presented as mean \pm SD.

[7], which confirms that OS plays a significant role in MS and implies that oxidative damage to blood serum proteins correlates with the severity of disease.

Melatonin (N-acetyl-5-methoxytryptamine; MEL) is a natural hormone derivative of tryptophan. In animals, it is synthesized primarily by pinealocytes of the pineal gland and regulates sleep and wakefulness. Melatonin is known as a scavenger of reactive oxygen and nitrogen species and an agent decreasing ROS generation as well as increasing the activity of antioxidant enzymes and glutathione content [8]. More and more studies have reported that MEL can improve memory impairment as a result of its antioxidant properties, which indicates that MEL may have a beneficial role in the treatment of neurodegenerative disorders involving enhanced OS [9-12].

Furthermore, MEL reduced clinical scores as well as ROS generation and delayed manifestation of motor symptoms in experimental autoimmune encephalomyelitis, which is an often used animal MS model. MEL also restored increased levels of microglia and CD4+ T cells in untreated animals to the control level and decreased the loss of oligodendrocytes, demyelination, and axonal injury [13].

In view of the occurrence and postulated role of OS in MS, examination of the effects of antioxidants in combination with standard treatment seems noteworthy. This study was aimed at examining the effect of MEL on the OS markers in MS patients treated with interferon beta-1b, basing mainly on the oxidative modifications of serum proteins as sensitive markers of OS $[14,15]$.

\section{Patients and Methods}

2.1. Patients. The study was approved by the local Ethics Committee of the Medical University of Silesia (KNW/ $0022 / \mathrm{KB} 1 / 130 / 12)$. Informed consent was obtained from all individual participants included in the study. After obtaining informed consent, demographic data, Kurtzke's Expanded Disability Status Scale (EDSS) [16], and MRI examinations were performed in all MS patients at the beginning of the study, in accordance with standard clinical protocols. Neurological examination was performed by a qualified neurologist using the EDSS before the therapy and after its completion.
We excluded patients with the following chronic disorders: diabetes, obesity (BMI over 30), hormonal, urinary or liver abnormalities, infectious or inflammatory diseases, dyslipidemia, and smoking. We also excluded patients taking antioxidant substances, vitamins, or anti-inflammatory medications, as well as those who received hormonal treatment within the last 3 months before the study and those who took sleeping medication in the last 2 weeks before the study.

The patients were divided into the following groups:

(i) Control group consisted of 11 healthy controls observed in the Department of Neurology in Zabrze, Medical University of Silesia, Poland, due to undiagnosed headaches. Controls were matched for age and sex with the study group.

(ii) RRMS untreated group was composed of 14 de novo diagnosed patients, with the relapsing-remitting form of MS (RRMS), according to the McDonald criteria (2005) [17], with immunomodifying pretreatment, but without any immunomodifying MS treatment.

(iii) RRMS INF-beta group was composed of 36 patients with RRMS, diagnosed according to the McDonald criteria. All of them received interferon beta- $1 \mathrm{~b}$ [Betaferon $(250 \mu \mathrm{g}$ injected subcutaneously every other day)].

(iv) RRMS INF-beta + MEL group consisted of 25 RRMS patients receiving interferon beta- $1 \mathrm{~b}$ injected subcutaneously every other day supplemented orally with MEL, $5 \mathrm{mg}$ per day, over a period of 90 days.

Demographic characteristics of the studied groups are presented in Table 1.

2.2. Materials. All basic reagents were from Sigma-Aldrich (Poznań, Poland), unless indicated otherwise. Fluorimetric and absorptiometric measurements were done in a Tecan Infinite 200 PRO multimode reader (Tecan Group Ltd., Männedorf, Switzerland) or in an EnVision Multilabel Plate Reader (Perkin-Elmer, Überlingen, Germany). All measurements were performed in triplicate and repeated a minimum of three times. 
2.3. MRI Examination. Head magnetic resonance imaging (MRI) was performed in all MS patients at the beginning of the study. The $1.5 \mathrm{~T}$ scanner imaging (General Electric HDx, USA) and standard head protocol for MS patients (multiple planes, slice thickness $5 \mathrm{~mm}$, contrast media: Gadovist [Gd]) and additional postcontrast 3DT1 sequences ( $1 \mathrm{~mm}$ slice thickness) were used. Supratentorial, infratentorial, and number of enhancing T1 plaques were evaluated.

2.4. Blood Sampling. Samples of venous blood $(10 \mathrm{ml})$ from MS patients and controls were collected into serumseparating tubes and immediately centrifuged to isolate serum. Collected serum samples were stored at $-80^{\circ} \mathrm{C}$ until biochemical analysis, for not more than 2 months. They were thawed at room temperature only once at the time of analysis.

2.5. Estimation of Protein Carbonyls. The content of protein carbonyls was estimated using OxiSelect ${ }^{\mathrm{TM}}$ Protein Carbonyl Fluorometric Assay Kit (Cell Biolabs Inc.) according to the protocol supplied by the manufacturer.

2.6. Estimation of Protein Oxidative Modifications. Products of oxidative modifications of proteins were estimated on the basis of their characteristic fluorescence. Fluorescence measurements were done by applying $150 \mu \mathrm{l}$ of the serum diluted 1:50 with phosphate-buffered saline (PBS; 1 tablet of $\mathrm{PBS} / 100 \mathrm{ml} \mathrm{H}_{2} \mathrm{O}$ ) to wells of a 96-well plate. Fluorescence was measured at wavelengths of $325 / 440 \mathrm{~nm}$ (AGEs), 330/415 nm (dityrosine), 325/434 nm ( $\mathrm{N}^{\prime}$-formylkynurenine), 365/480 nm (kynurenine), and 295/340 nm (tryptophan) $[14,15]$.

2.7. Estimation of Thiol Groups. Thiol groups were estimated using a modification of the Ellman's method [18]. Samples $(20 \mu \mathrm{l})$ were pipetted to wells of a 96-well plate containing $100 \mu \mathrm{l}$ of $0.1 \mathrm{M}$ phosphate buffer, $\mathrm{pH}$ 8.0. Afterwards, $2 \mu \mathrm{l}$ of $10 \mathrm{mg} / \mathrm{ml}$ Ellman's reagent [5,5'dithiobis-(2-nitrobenzoic acid); DTNB] was added. Absorbance was measured after $1 \mathrm{~h}$ incubation in the dark at $37^{\circ} \mathrm{C}$ at the wavelength of $412 \mathrm{~nm}$ against a reagent blank. The thiol group content was calculated on the basis of a standard curve using glutathione as a standard.

2.8. Estimation of Protein. The protein concentration was estimated using the method of Lowry et al. [19]. Serum diluted 200 times with PBS $(100 \mu \mathrm{l})$ was mixed with $500 \mu \mathrm{l}$ of the Lowry reagent (formed by mixing $30 \mathrm{ml}$ of $2 \% \mathrm{Na}_{2} \mathrm{CO}_{3}$ in $0.1 \mathrm{M} \mathrm{NaOH}, 0.6 \mathrm{ml}$ of $5 \% \mathrm{C}_{4} \mathrm{H}_{4} \mathrm{O}_{6} \mathrm{KNa} \cdot 4 \mathrm{H}_{2} \mathrm{O}$, and $0.6 \mathrm{ml}$ of $2 \% \mathrm{Cu}_{2} \mathrm{SO}_{4}$ ) and incubated at room temperature for $10 \mathrm{~min}$. Afterwards, $50 \mu \mathrm{l}$ of the Folin-Ciocalteu reagent was added; the plate was shaken and incubated at room temperature for $30 \mathrm{~min}$. The absorbance was measured at $750 \mathrm{~nm}$. Standard curve was prepared with human serum albumin $(0-300 \mu \mathrm{g} / \mathrm{ml})$.

2.9. Estimation of Malondialdehyde (MDA). The serum samples $(50 \mu \mathrm{l}$ serum plus $50 \mu \mathrm{l}$ PBS or $100 \mu \mathrm{l}$ PBS blank) were mixed with ice-cold $200 \mu \mathrm{l}$ of mixture $(1: 1)$ of $0.37 \%$ thiobarbituric acid (TBA) and 15\% trichloroacetic acid (TCA) in $0.25 \mathrm{M} \mathrm{HCl}$ to precipitate protein. The reaction was performed at $\mathrm{pH} 2-3$ at $100^{\circ} \mathrm{C}$ for $40 \mathrm{~min}$. The precipitate was pelleted by centrifugation at $3000 \times \mathrm{g}$ at $4^{\circ} \mathrm{C}$ for $10 \mathrm{~min}$. Absorbance of supernatants was read at a wavelength of $532 \mathrm{~nm}$.

The majority of TBA-reactive substances (TBARS) is malondialdehyde; thus, the concentration of MDA in blood serum was expressed as $\mu \mathrm{M}$ MDA. The results were calculated using an absorption coefficient for MDA of $1.56 \times 10^{5} \mathrm{M}^{-1} \mathrm{~cm}^{-1}$.

2.10. Estimation of AOPP. Advanced oxidation protein products (AOPP) were estimated using the method of Witko-Sarsat et al. [20]. $200 \mu \mathrm{l}$ of serum diluted 1:5 with PBS was applied to a 96-well plate, and $20 \mu \mathrm{l}$ of acetic acid was added to each well. Absorbance was measured at $340 \mathrm{~nm}$ against a blank containing $200 \mu \mathrm{l}$ of PBS, $20 \mu \mathrm{l}$ of acetic acid, and $10 \mu \mathrm{l}$ of $1.16 \mathrm{M}$ potassium iodide. Calibration curve was prepared using chloramine- $\mathrm{T}$ at concentrations of $0-100 \mu \mathrm{M}$ by applying $200 \mu \mathrm{l}$ chloramine-T, $20 \mu \mathrm{l}$ acetic acid, and $10 \mu \mathrm{l}$ of $1.16 \mathrm{M}$ potassium iodide to the plate. AOPP concentration is expressed in nmol chloramine-T-equivalents/ mg protein.

2.11. Estimation of Total Antioxidant Capacity of Blood Serum as FRAP. Total antioxidant status was measured in serum using the ferric reducing antioxidant power assay (FRAP). The ferric reducing antioxidant potential assay measures the ability of antioxidants to reduce ferric $\left(\mathrm{Fe}^{3+}\right)$ ions to ferrous $\left(\mathrm{Fe}^{2+}\right)$ ions [21]. $0.3 \mathrm{M}$ acetate buffer $(\mathrm{pH}=3.6)$, $0.01 \mathrm{M}$ TPTZ (2,4,6-tripyridyl-s-triazine) in $0.04 \mathrm{M} \mathrm{HCl}$, and $0.02 \mathrm{M} \mathrm{FeCl}_{3}{ }^{*} 6 \mathrm{H}_{2} \mathrm{O}$ mixed in $10: 1: 1$ and $180 \mu \mathrm{l}$ of this mixture were added to wells of a 96 -well plate containing $10 \mu \mathrm{l}$ of sample and $10 \mu \mathrm{l}$ of PBS. The reduction of $\mathrm{Fe}^{3+}$ -2,4,6-tripyridyl-s-triazine complex to the ferrous form at low $\mathrm{pH}$ was monitored by measuring the absorption change after $20 \mathrm{~min}$ incubation at room temperature at $593 \mathrm{~nm}$. The value was calculated relevant to the activity of Trolox and expressed as $\mu$ moles Trolox equivalents/l $(\mu \mathrm{M})$.

2.12. Estimation of Total Antioxidant Capacity with ABTS*. Antiradical activity is a measure of the ability of a given compound to react with free radicals. One stable free radical employed in such reactions is the 2,2'-azinobis(3-ethylbenzthiazoline-6-sulfonic acid) radical (ABTS*). Standard antioxidants react rapidly with ABTS* (within seconds; "fast antioxidants") while some react at a lower rate ("slow antioxidants") [22]. Briefly, $2 \mu \mathrm{l}$ of sample and $18 \mu \mathrm{l}$ of PBS were added to a solution of ABTS*, diluted such that $200 \mu \mathrm{l}$ of the solution had absorbance of 1.0 in a microplate well. The decrease in ABTS* absorbance was measured after $1 \mathrm{~min}$ ("fast" scavenging) and between 10 and 30 min ("slow" scavenging) of incubation at ambient temperature $\left(21 \pm 1^{\circ} \mathrm{C}\right)$ at $414 \mathrm{~nm}$. ABTS* scavenging activity was calculated relevant to the activity of Trolox and expressed as $\mu$ moles Trolox equivalents/l $(\mu \mathrm{M})$.

2.13. Statistical Analysis. All experiments were performed in triplicate. Data are shown in the form of arithmetic mean values and standard deviations. Statistical analysis was done using one-way analysis of variance (ANOVA/Dunnett's test) for multiple samples and Student's $t$-test for comparing 
paired sample sets. $p$ values less than 0.05 were considered statistically significant. The statistical analysis of the data was performed using STATISTICA (version 12.5, StatSoft Inc. 2XXX, Tulsa, OK, USA, http://www.statsoft.com).

\section{Results and Discussion}

There are several amino acid residues in proteins which are most sensitive to oxidative insult: first of all, cysteine, tryptophan, and tyrosine residues. The decrease in the level of these residues and increase in the level of their modification products are useful biomarkers of OS in vitro and in vivo.

The level of thiol groups in blood serum reflects predominantly the cysteine thiol groups of serum proteins. The level of thiol groups in the serum, expressed both as thiol concentration and the thiol content of serum proteins, decreased in nontreated patients (from $0.58 \pm 0.05$ to $0.52 \pm 0.09 \mathrm{mM}$ and from $0.52 \pm 0.09$ to $6.84 \pm 0.95 \mathrm{nmol} / \mathrm{mg}$ protein, resp.), and the magnitude of this decrease was attenuated in patients treated with INF-beta and INF-beta plus MEL. However, these changes were devoid of statistical significance (not shown).

As a result of OS, the level of tryptophan fluorescence decreases and the levels of products of oxidative destruction of tryptophan such as kynurenine and $\mathrm{N}^{\prime}$-formylkynurenine, easily detectable by fluorescence, increased.

The values of tryptophan fluorescence decreased in the nontreated patients to $94.9 \pm 8.4 \%$ of the control value. This decrease was attenuated in patients treated with INF-beta-1b and INF-beta plus MEL, but all these changes lacked statistical significance (not shown).

The content of $\mathrm{N}^{\prime}$-formylkynurenine in blood serum proteins of nontreated MS patients was significantly increased with respect to control $(p<0.001)$. Treatment with INFbeta plus MEL prevented this increase $(p<0.001)$, while treatment with INF-beta alone was ineffective (Figure 1).

The content of kynurenine in blood serum proteins of nontreated MS patients was significantly increased with respect to control $(p<0.05)$. Treatment with INF-beta plus MEL prevented this increase $(p<0.01)$, while treatment with INF-beta alone was again ineffective (Figure 2).

Tyrosine residues are other residues in proteins sensitive to oxidation and also to nitration. Free radical oxidation of tyrosine creates tyrosyl radicals; dimerization of tyrosyl radicals forms dityrosine, which can also be estimated on the basis of its characteristic fluorescence.

The level of dityrosine in blood serum proteins of nontreated MS patients was significantly elevated with respect to control $(p<0.001)$. Treatment with INF-beta $(p<0.01)$ and especially with INF-beta plus MEL $(p<0.001)$ eliminated this elevation (Figure 3).

Protein carbonylation is perhaps the most commonly studied oxidative protein modification induced by ROS. It usually refers to a process that produces reactive ketone or aldehyde residues on proteins that can react with 2,4-dinitrophenylhydrazine (DNPH) to form hydrazones. Protein carbonylation can occur via two ways, as "primary protein carbonylation" by direct oxidation of side chains of some amino acid residues, initiated by ROS and usually metal-

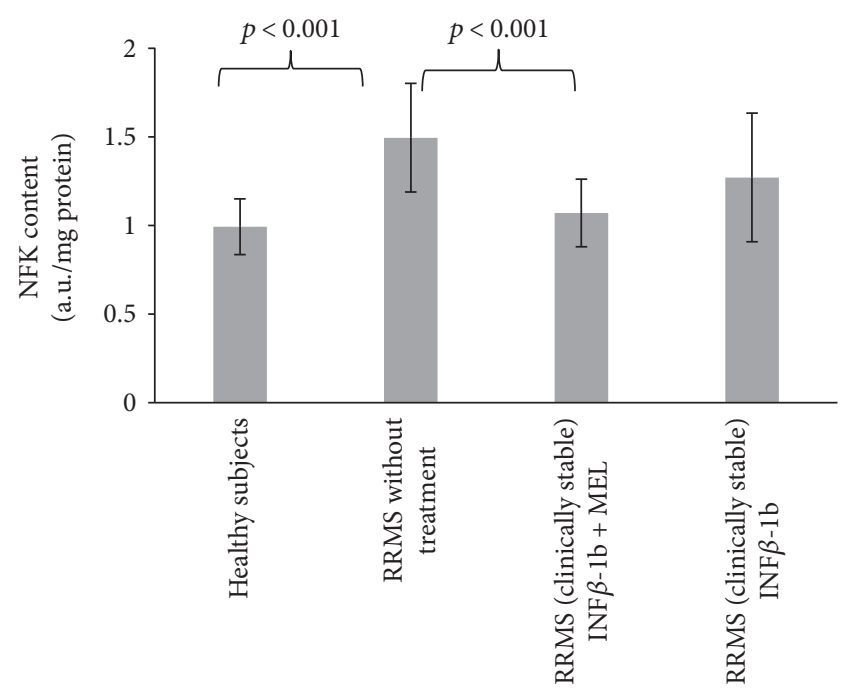

FIGURE 1: Comparison of $\mathrm{N}^{\prime}$-formylkynurenine content of blood serum proteins in healthy controls, in RRMS patients without treatment, in RRMS patients treated with INF-beta, and in RRMS patients treated with INF-beta plus MEL. If not indicated, differences are not statistically significant.

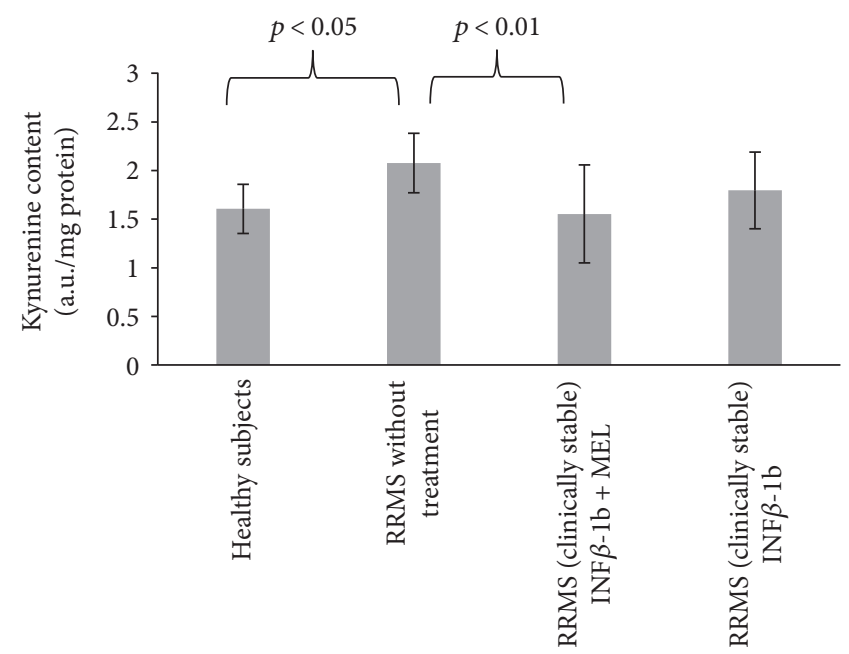

FIgURE 2: Comparison of kynurenine content of blood serum proteins in healthy controls, in RRMS patients without treatment, in RRMS patients treated with INF-beta, and in RRMS patients treated with INF-beta plus MEL.

catalyzed, and by "secondary protein carbonylation" via addition of aldehydes, generated mainly from lipid peroxidation, such as 4-hydroxynonenal (4-HNE), 2-propenal (acrolein), and malondialdehyde, as well as carbonylbearing products of sugar glycoxidation [23, 24].

The level of protein carbonyls increased in nontreated patients with respect to control $(p<0.001)$; this increase was significantly attenuated $(p<0.05)$ in patients treated with INF-beta plus MEL. The level of protein carbonyls was also decreased in patients treated with only INF-beta, but the decrease was not statically significant with respect to nontreated patients (Figure 4). 


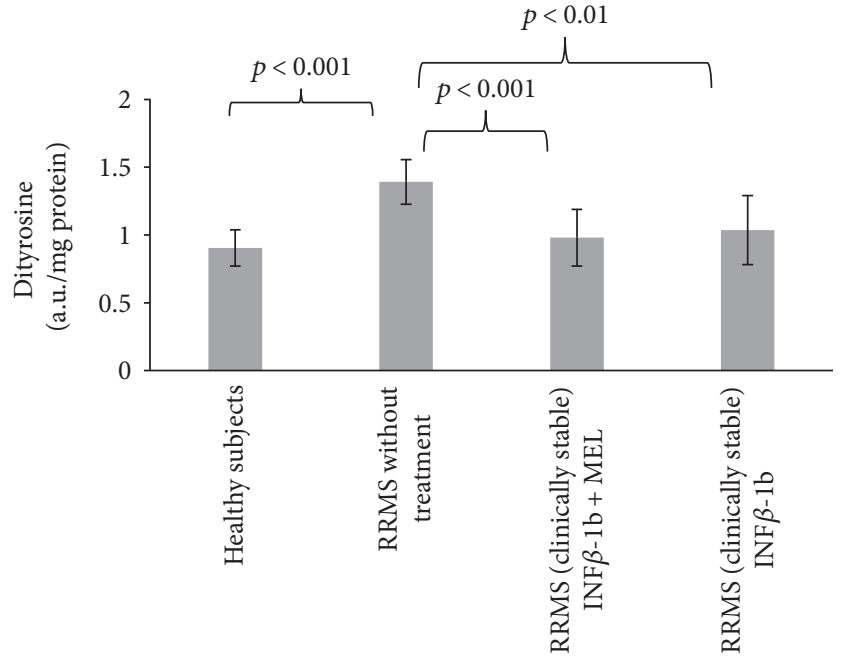

FIgURE 3: Comparison of dityrosine content of blood serum proteins in healthy controls, in RRMS patients without treatment, in RRMS patients treated with INF-beta, and in RRMS patients treated with INF-beta plus MEL.

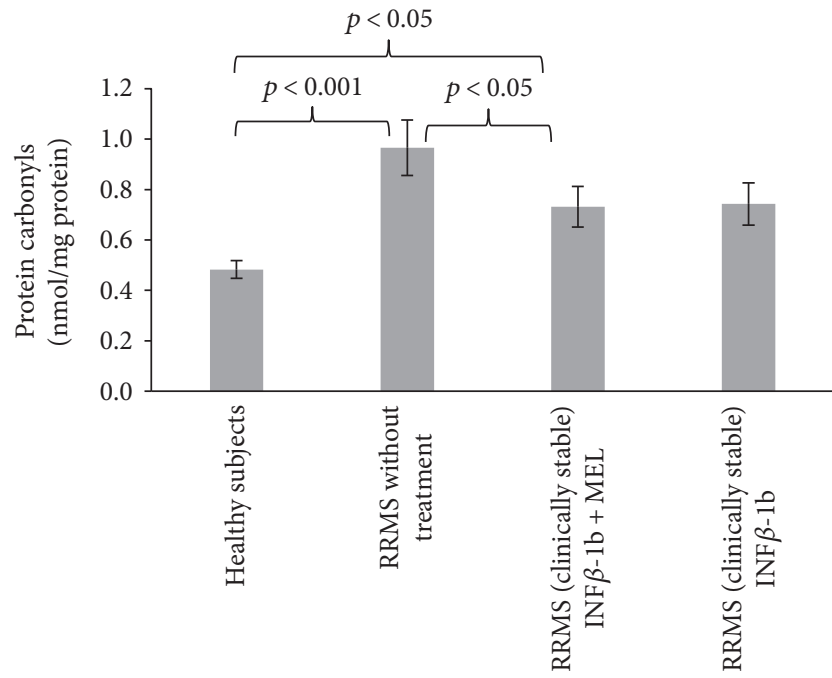

Figure 4: Comparison of carbonyl content of blood serum proteins in healthy controls, in RRMS patients without treatment, in RRMS patients treated with INF-beta, and in RRMS patients treated with INF-beta plus MEL.

Reaction of glycoxidation end products (AGEs) with proteins leads to formation of products with characteristic fluorescence. The fluorescence of AGEs in blood serum proteins of nontreated MS patients was significantly elevated with respect to control $(p<0.01)$. Treatment with INF-beta and MEL prevented this elevation $(p<0.001)$, while the effect of INF-beta alone was devoid of statistical significance (Figure 5).

The reasons for increase in the AGE fluorescence seem to be unclear as the glucose level is not increased in the patients. It may be perhaps attributed to the acceleration of protein glycation by OS demonstrated to occur in vitro [25]. The majority of AGEs in vivo are mainly formed in a fast reaction

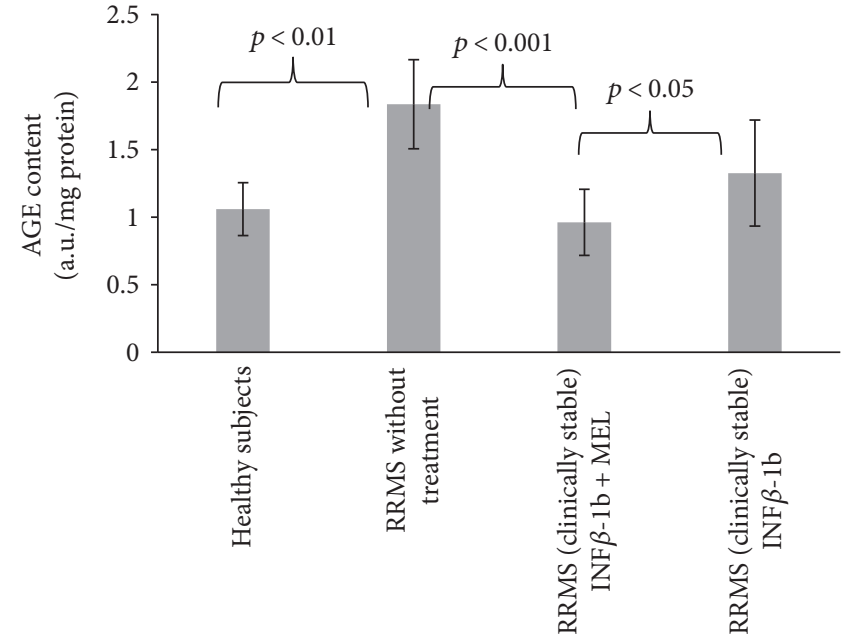

FIGURE 5: Comparison of AGE content of blood serum proteins in healthy controls, in RRMS patients without treatment, in RRMS patients treated with INF-beta, and in RRMS patients treated with INF-beta and MEL.

of dicarbonyl compounds, such as methylglyoxal (MGO) and glyoxal, with proteins. Furthermore, the main detoxification system of dicarbonyl compounds, the glyoxalase system, seems to be affected in MS patients, which may contribute to high MGO-derived AGE levels [26]. Advanced glycation end products are increased in inflammatory diseases such as atherosclerosis, obesity, and diabetes and also in neuroinflammatory diseases such as Alzheimer's disease and Parkinson's disease. It was reported that AGEs are increased in the plasma and CNS of MS patients [26, 27]. Wetzels et al. [26] suggested that the accumulation of AGEs in the plasma and central nervous system of MS patients compared to healthy controls may contribute to neuroinflammation and the progression of MS.

Advanced oxidation protein products (AOPP) consist of oxidized, dityrosine-containing, crosslinked proteins formed mainly by reactions of reactive chlorine species with plasma proteins [28]. The level of AOPP was increased in the nontreated patients $(p<0.05)$; this increase was attenuated in patients treated with INF-beta and INF-beta plus MEL (Figure 6).

Oxidative stress in MS patients was also assessed on the basis of standard parameters such as the level of malondialdehyde (MDA) and total antioxidant capacity of blood serum.

The MDA concentration in blood serum was elevated in the nontreated patients, but treatment with either INF-beta or INF-beta plus melatonin did not attenuate this increase (Figure 7).

Blood serum FRAP was decreased in nontreated MS patients from $368.6 \pm 77.7$ to $318.0 \pm 77.8 \mu \mathrm{M}$ Trolox equivalents; this decrease was attenuated especially in patients treated with INF-beta plus MEL $(378.0 \pm 112.8 \mu \mathrm{M}$ Trolox equivalents), but all these changes lacked statistical significance.

"Fast" ABTS* scavenging activity of blood serum was decreased in the patients with respect to control subjects, 


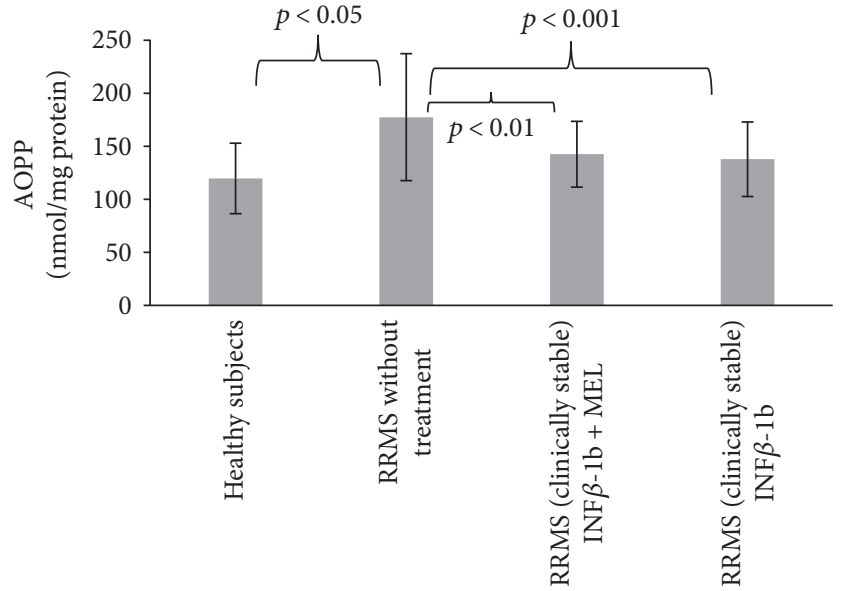

Figure 6: Comparison of AOPP content of blood serum proteins in healthy controls, in RRMS patients without treatment, in RRMS patients treated with INF-beta, and in RRMS patients treated with INF-beta and MEL.

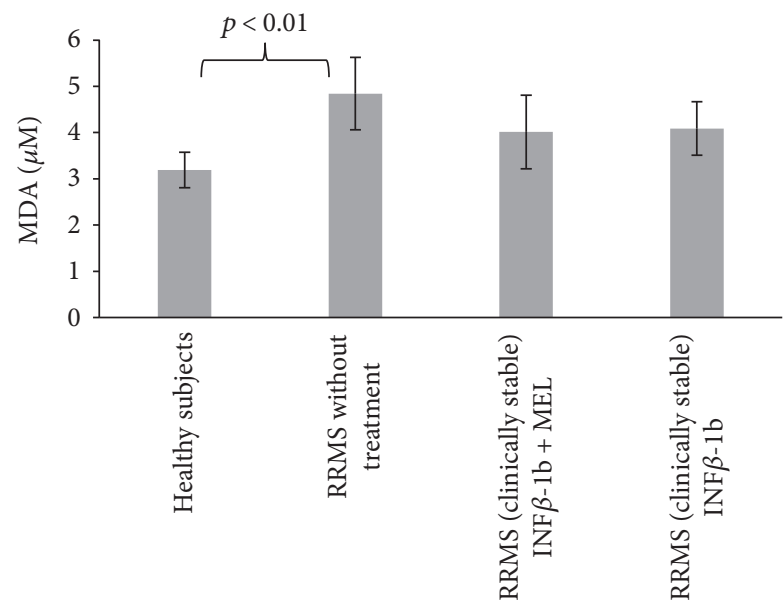

FIGURE 7: Comparison of malondialdehyde concentration in blood serum proteins in healthy controls, in RRMS patients without treatment, in RRMS patients treated with INF-beta, and in RRMS patients treated with INF-beta and MEL.

but this decrease was devoid of statistical activity. However, treatment with INF-beta and with INF-beta plus MEL caused significant elevation of this activity $(p<0.001$ and $p>0.01$, resp.). MEL alone could not contribute significantly to the ABTS* scavenging activity of blood serum as its submicromolar concentrations attainable in vivo are insignificant with respect to other contributing compounds [29]. "Slow" ABTS* scavenging activity was increased in the nontreated patients (devoid of statistical significance); treatment with either INF-beta or INF-beta plus MEL decreased "slow" ABTS-scavenging activity ( $p<0.001$ in both cases; Figure 8$)$.

It is not obvious what determines the "slow" ABTS* scavenging activity of blood serum. Amino acids such as tryptophan and tyrosine show this type of reactivity [22]. It is possible that the increase in the "slow" ABTS* scavenging activity may be due to leakage of some intracellular slowly reacting antioxidants.

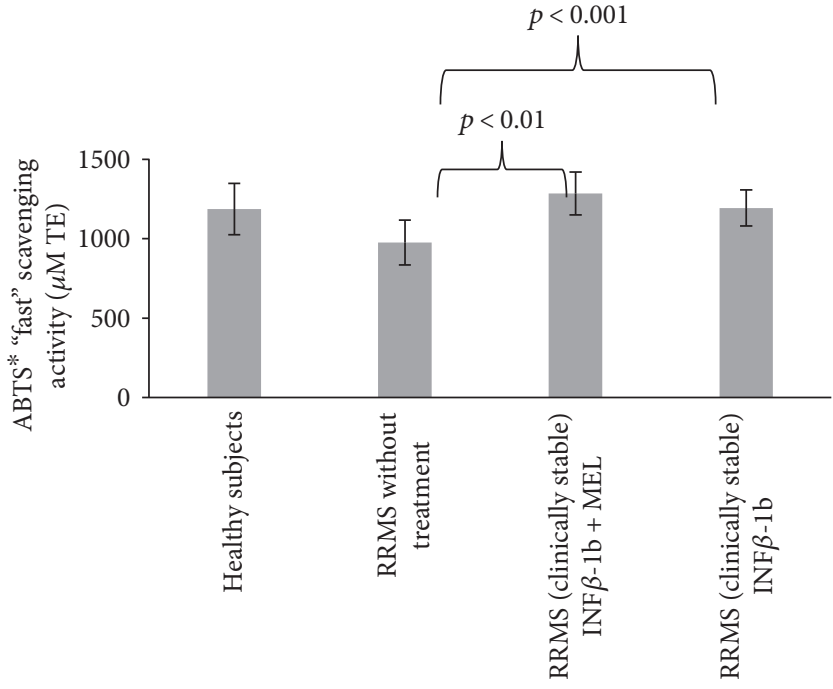

(a)

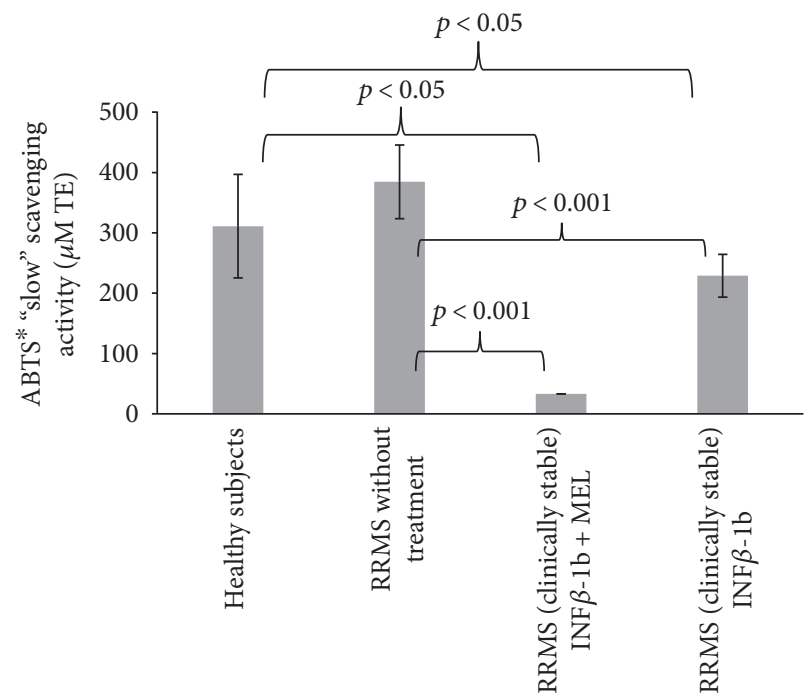

(b)

FIgURE 8: Comparison of "fast" (a) and "slow" (b) ABTS* scavenging activity of blood serum proteins in healthy controls, in RRMS patients without treatment, in RRMS patients treated with INF-beta, and in RRMS patients treated with INF-beta and MEL.

In summary, the study corroborates the usefulness of protein oxidative modifications as sensitive markers of OS in MS. Our results confirm also previous findings on the occurrence of OS treatment of MS and attenuation of OS by INF-beta treatment, judging from the levels of oxidative modifications of blood serum proteins $[14,15]$. The antioxidant effect of INF-beta is due to its immunomodulatory and anti-inflammatory action [1]. Combined treatment with INF-beta and melatonin was more effective in attenuating oxidative stress, being effective in diminishing the increase in the levels of $\mathrm{N}^{\prime}$-formylkynurenine, kynurenine, carbonyl, and AGE content where treatment with INF-beta alone was ineffective. These results confirm our previous finding on the attenuation of OS in MS patients treated with INF-beta and MEL, on the basis of reduction of lipid plasma hydroperoxide level [30]. 
It does not seem probable that the attenuation of OS by MEL in MS patients is due to the direct antioxidant activity of this compound, as discussed above. However, MEL is also an indirect antioxidant, acting via stimulation of biosynthesis of antioxidants and other protective proteins, which may be the major mechanisms of its action. MEL was shown to increase the level of expression of genes coding for catalase, MnSOD, and sirtuin 1 [31] and is known to regulate the mitochondrial bioenergetic function [32]. Moreover, MEL directly interferes with the differentiation of $\mathrm{T}$ cells, inducing the expression of the repressor transcription factor Nfil3, blocking the differentiation of pathogenic Th17 cells and boosting the generation of protective $\operatorname{Tr} 1$ cells via Erk1/2 and the transactivation of the IL- 10 promoter by ROR- $\alpha$ [33]; MEL inhibits also demyelination and increases remyelination [34]. These multiple effects of MEL may, apart from its antioxidant effects, contribute to its positive effects in MS $[1,30,33,35]$.

\section{Conclusion}

This study demonstrates that MEL administration to MS patients undergoing therapy with INF-beta ameliorates oxidative stress, decreasing the extent of the majority of protein oxidative modifications examined. These results support the view that combined administration of INF-beta and MEL can be more effective in reducing oxidative stress in MS patients than INF-beta alone.

\section{Conflicts of Interest}

The authors have no conflicts to disclose.

\section{Authors' Contributions}

Izabela Sadowska-Bartosz was responsible for the concept and design of the experiments and supervision of experimental work, performed part of the experiments, and had a leading role in the analysis of the results and preparation of the manuscript. Monika Adamczyk-Sowa and Paweł Sowa participated in the design of the experiments and were responsible for patient recruitment, clinical characterization of the patients, and collection of blood samples. Sabina Galiniak performed part of the experiments and their statistical evaluation. Ewa Żyracka, Michalina Grzesik, and Katarzyna Naparło performed part of the experiments. Grzegorz Bartosz participated in the preparation of the manuscript. All authors have approved the final manuscript.

\section{Acknowledgments}

The authors are indebted to Mrs. Edyta Bieszczad-Bedrejczuk, M.Sc., for her technical help.

\section{References}

[1] S. Dhib-Jalbut, "Mechanisms of action of interferons and glatiramer acetate in multiple sclerosis," Neurology, vol. 58, no. 8, Supplement 4, pp. S3-S9, 2002.
[2] S. Dhib-Jalbut and S. Marks, "Interferon- $\beta$ mechanisms of action in multiple sclerosis," Neurology, vol. 74, Supplement 1, pp. S17-S24, 2010.

[3] L. Haider, M. T. Fischer, J. M. Frischer et al., "Oxidative damage in multiple sclerosis lesions," Brain, vol. 134, no. 7, pp. 1914-1924, 2011.

[4] P. Wang, K. Xie, C. Wang, and J. Bi, "Oxidative stress induced by lipid peroxidation is related with inflammation of demyelination and neurodegeneration in multiple sclerosis," European Neurology, vol. 72, no. 3-4, pp. 249-254, 2014.

[5] F. Mir, D. Lee, H. Ray, and S. A. Sadiq, "CSF isoprostane levels are a biomarker of oxidative stress in multiple sclerosis," Neurology-Neuroimmunology Neuroinflammation, vol. 1, no. 2, article e21, 2014.

[6] S. R. Oliveira, A. P. Kallaur, A. N. Simão et al., "Oxidative stress in multiple sclerosis patients in clinical remission: association with the expanded disability status scale," Journal of the Neurological Sciences, vol. 321, no. 1-2, pp. 49-53, 2012.

[7] A. Fiorini, T. Koudriavtseva, E. Bucaj et al., "Involvement of oxidative stress in occurrence of relapses in multiple sclerosis: the spectrum of oxidatively modified serum proteins detected by proteomics and redox proteomics analysis," PLoS One, vol. 8, no. 6, article 65184, 2013.

[8] S. Mehrzadi, M. Safa, S. K. Kamrava, R. Darabi, P. Hayat, and M. Motevalian, "Protective mechanisms of melatonin against hydrogen-peroxide-induced toxicity in human bonemarrow-derived mesenchymal stem cells," Canadian Journal of Physiology and Pharmacology, vol. 95, no. 7, pp. 773-786, 2016.

[9] S. R. Pandi-Perumal, A. S. BaHammam, G. M. Brown et al., "Melatonin antioxidative defense: therapeutical implications for aging and neurodegenerative processes," Neurotoxicity Research, vol. 23, no. 3, pp. 267-300, 2013.

[10] U. Rimmele, M. Spillmann, C. Bärtschi et al., "Melatonin improves memory acquisition under stress independent of stress hormone release," Psychopharmacology, vol. 202, no. 4, pp. 663-672, 2009.

[11] G. Baydas, M. Özera, A. Yasara, M. Tuzcu, and S. T. Koz, "Melatonin improves learning and memory performances impaired by hyperhomocysteinemia in rats," Brain Research, vol. 1046, no. 1-2, pp. 187-194, 2005.

[12] R. Sharif, M. Aghsami, M. Gharghabi et al., "Melatonin reverses H-89 induced spatial memory deficit: involvement of oxidative stress and mitochondrial function," Behavioural Brain Research, vol. 316, pp. 115-124, 2017.

[13] J. Wen, P. S. Ariyannur, R. Ribeiro et al., "Efficacy of Nacetylserotonin and melatonin in the EAE model of multiple sclerosis," Journal of Neuroimmune Pharmacology, vol. 11, no. 4, pp. 763-773, 2016.

[14] I. Sadowska-Bartosz, M. Adamczyk-Sowa, S. Galiniak, S. Mucha, K. Pierzchala, and G. Bartosz, "Oxidative modification of serum proteins in multiple sclerosis," Neurochemistry International, vol. 63, no. 4, pp. 507-516, 2013.

[15] I. Sadowska-Bartosz, M. Adamczyk-Sowa, A. Gajewska, and G. Bartosz, "Oxidative modification of blood serum proteins in multiple sclerosis after interferon or mitoxantrone treatment," Journal of Neuroimmunology, vol. 266, no. 1-2, pp. 67-74, 2014.

[16] J. F. Kurtzke, "Rating neurologic impairment in multiple sclerosis: an expanded disability status scale (EDSS)," Neurology, vol. 33, no. 11, pp. 1444-1452, 1983. 
[17] P. Schwenkenbecher, A. Sarikidi, U. Wurster et al., "McDonald criteria 2010 and 2005 compared: persistence of high oligoclonal band prevalence despite almost doubled diagnostic sensitivity," International Journal of Molecular Sciences, vol. 17, no. 9, article 1592, 2016.

[18] G. L. Ellman, “Tissue sulfhydryl groups,” Archives of Biochemistry and Biophysics, vol. 82, no. 1, pp. 70-77, 1959.

[19] O. H. Lowry, N. J. Rosebrough, A. L. Farr, and R. J. Randall, "Protein measurement with the Folin phenol reagent," The Journal of Biological Chemistry, vol. 193, no. 1, pp. 265-275, 1951.

[20] V. Witko-Sarsat, M. Friedlander, C. Capeillère-Blandin et al., "Advanced oxidation protein products as a novel marker of oxidative stress in uremia," Kidney International, vol. 49, no. 5, pp. 1304-1313, 1996.

[21] I. F. Benzie and J. J. Strain, "The ferric reducing ability of plasma (FRAP) as a measure of "antioxidant power": the FRAP assay," Analytical Biochemistry, vol. 239, no. 1, pp. 7076, 1996.

[22] G. Bartosz, "Total antioxidant capacity," Advances in Clinical Chemistry, vol. 37, pp. 219-292, 2003.

[23] I. Dalle-Donne, R. Rossi, D. Giustarini, A. Milzani, and R. Colombo, "Protein carbonyl groups as biomarkers of oxidative stress," Clinica Chimica Acta, vol. 329, no. 1-2, pp. 23-38, 2003.

[24] Y. J. Suzuki, M. Carini, and D. A. Butterfield, "Protein carbonylation," Antioxidants \& Redox Signaling, vol. 12, no. 3, pp. 323-325, 2010.

[25] A. Vlassopoulos, M. E. Lean, and E. Combet, "Role of oxidative stress in physiological albumin glycation: a neglected interaction," Free Radical Biology \& Medicine, vol. 60, pp. 318-324, 2013.

[26] S. Wetzels, K. Wouters, C. G. Schalwijk, T. Vanmierlo, and J. Hendriks, "Methylglyoxal-derived advanced glycation endproducts in multiple sclerosis," International Journal of Molecular Sciences, vol. 18, p. 421, 2017.

[27] Z. Sternberg, C. Hennies, D. Sternberg et al., "Diagnostic potential of plasma carboxymethyllysine and carboxyethyllysine in multiple sclerosis," Journal of Neuroinflammation, vol. 7, p. 72, 2017.

[28] V. Witko-Sarsat, M. Friedlander, T. Nguyen Khoa et al., "Advanced oxidation protein products as novel mediators of inflammation and monocyte activation in chronic renal failure," The Journal of Immunology, vol. 161, no. 5, pp. 25242532, 1998.

[29] A. Grzelak and G. Bartosz, "Melatonin does not affect total antioxidant capacity of blood plasma in vitro," Scandinavian Journal of Clinical and Laboratory Investigations, vol. 65, no. 1, pp. 77-81, 2005.

[30] M. Adamczyk-Sowa, P. Sowa, J. Adamczyk et al., "Effect of melatonin supplementation on plasma lipid hydroperoxides, homocysteine concentration and chronic fatigue syndrome in multiple sclerosis patients treated with interferons-beta and mitoxantrone," Journal of Physiology and Pharmacology, vol. 63, no. 5, pp. 507-516, 2013.

[31] S. Emamgholipour, A. Hossein-Nezhad, M. A. Sahraian, F. Askarisadr, and M. Ansari, "Evidence for possible role of melatonin in reducing oxidative stress in multiple sclerosis through its effect on SIRT1 and antioxidant enzymes," Life Sciences, vol. 145, pp. 34-41, 2016.
[32] S. A. Ganie, T. A. Dar, A. H. Bhat et al., "Melatonin: a potential anti-oxidant therapeutic agent for mitochondrial dysfunctions and related disorders," Rejuvenation Research, vol. 19, no. 1, pp. 21-40, 2016.

[33] M. F. Farez, I. D. Mascanfroni, S. P. Méndez-Huergo et al., "Melatonin contributes to the seasonality of multiple sclerosis relapses," Cell, vol. 162, no. 6, pp. 1338-1352, 2015.

[34] G. Anderson and M. Rodriguez, "Multiple sclerosis: the role of melatonin and N-acetylserotonin," Multiple Sclerosis and Related Disorders, vol. 4, no. 2, pp. 112-123, 2015.

[35] T. Roostaei, M. A. Sahraian, S. Hajeaghaee et al., "Impact of melatonin on motor, cognitive and neuroimaging indices in patients with multiple sclerosis," Iran Journal of Allergy, Asthma and Immunology, vol. 14, no. 6, pp. 589-595, 2015. 


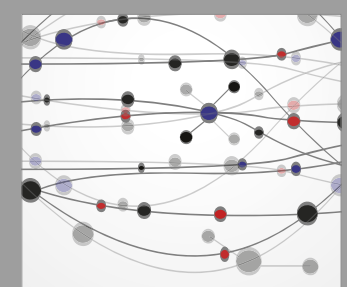

The Scientific World Journal
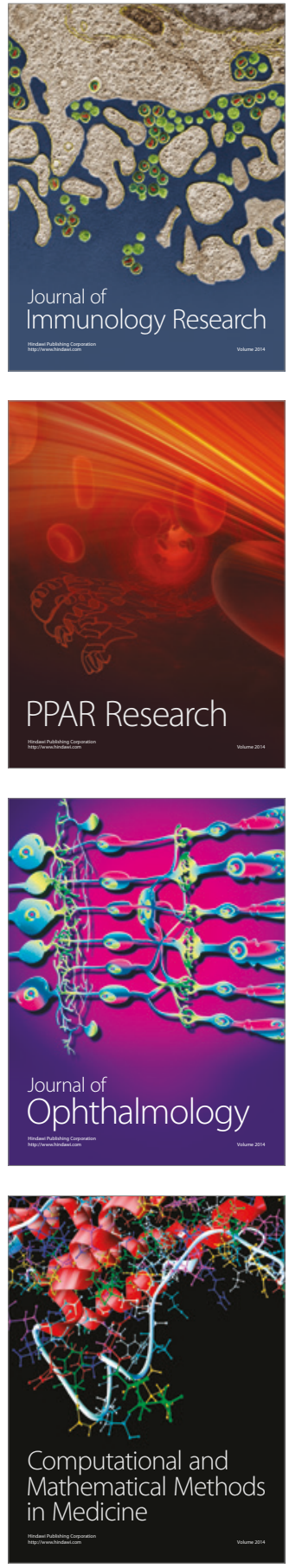

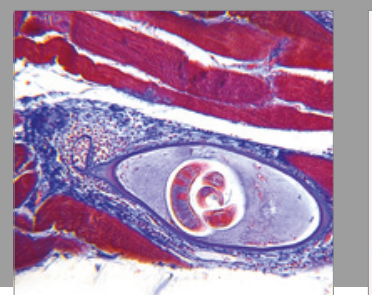

Gastroenterology Research and Practice
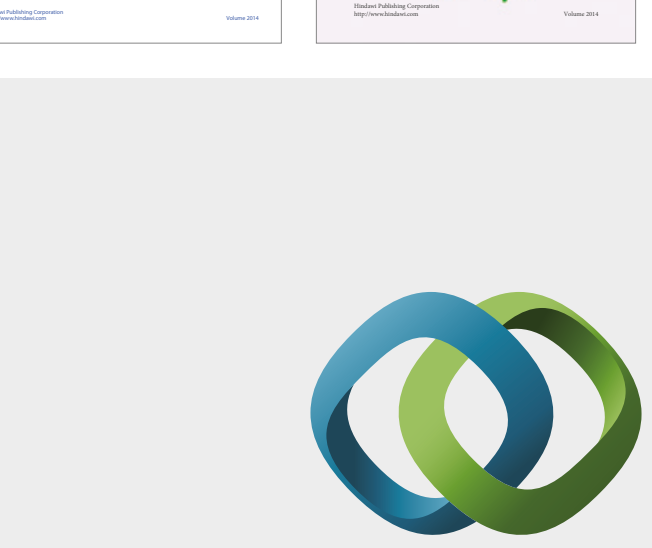

\section{Hindawi}

Submit your manuscripts at

https://www.hindawi.com
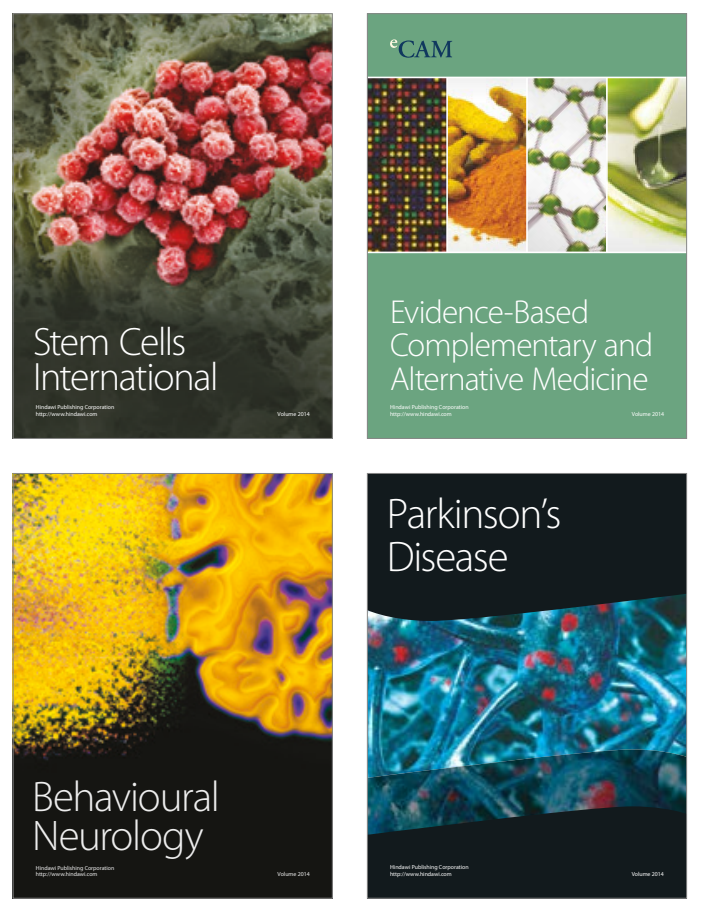
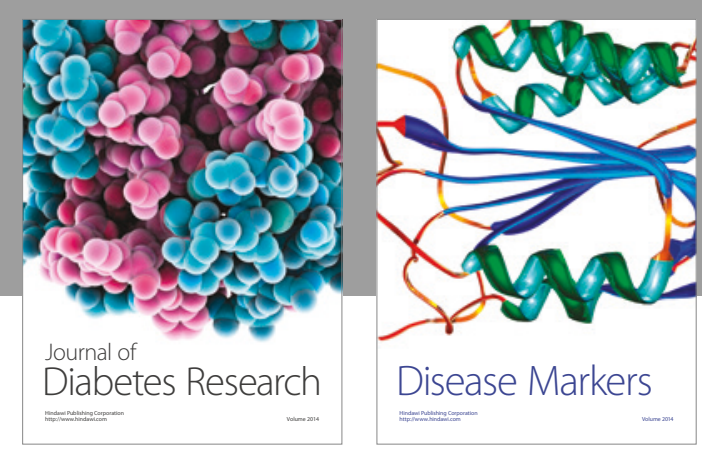

Disease Markers
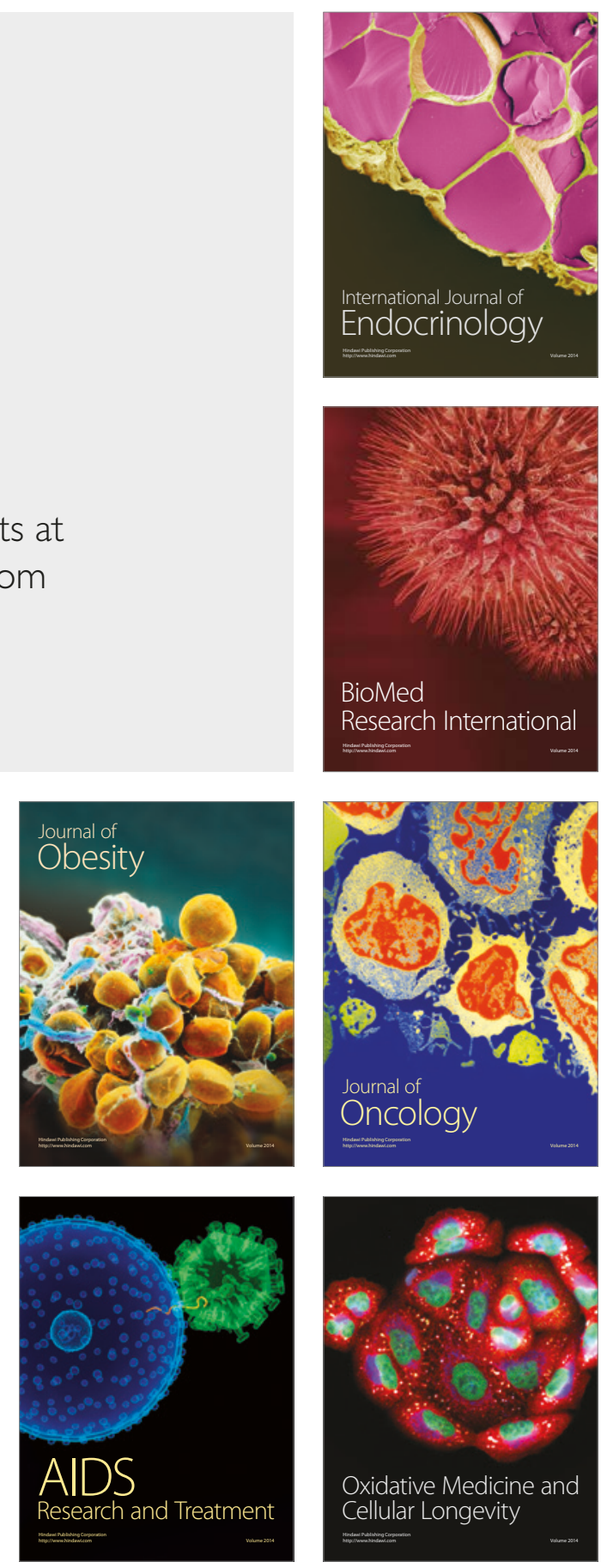